\title{
THE INFLUENCE OF SALIVARY GLAND EXTRACT (SGE) OF Anopheles sundaicus TO INTERLEUKIN 12 LEVEL OF THE WHITE MOUSE INFECTED WITH Plamodium berghei
}

\author{
Adrial $^{1}$, Ellyza Nasrul ${ }^{2}$, Rosfita Rasyid ${ }^{3}$ \\ adrial@med.unand.ac.id \\ ${ }^{1}$ Department of Parasitology Faculty of Medicine of Universitas Andalas, Padang, \\ Indonesia \\ ${ }^{2}$ Department Clinical Pathology Faculty of Medicine of Universitas Andalas, \\ Padang, Indonesia \\ ${ }^{3}$ Department of Public Health, Faculty of Medicine of Universitas Andalas, Padang, \\ Indonesia
}

\begin{abstract}
Malaria is an infectous disease which is still a major public health problem in the world. A main problem of management of malaria to date is a difficulty finding a effective vaccine providing the protection to people. Interleukin-12 is a potential immunomodilator cytokine having effectivity in the protection against viruses, bacteries and intercellular parasite infection as well as the main mediator from naturally immunity system to intracellular microbial, and is the key inducer from cellular immunity is the acquired imune responses to microbials. The aim to study is to know influence of salivary gland extract (SGE) of Anopheles sundaicus to IL-12 level in the white mouse Mus musculus Balb/C after infected with Plasmodium berghei. This research is the laboratory experimental studies with the post test control group design only using animal model as the investigation object. The samples is divided into the control group (mice immunized with adjuvant+PBS, ratio 1:1); The pellets extract group (the mice immunized by pellet of SGE of An. sundaicus + adjuvant, ratio 1:1); the supernathan extract group (the mice immunized by yhe extract of gland supernathan of An. sundaicus + adjuvant, ratio 1:1). The first immunization using CFA adjuvant and second immunization (booster 1) and the third immunization (booster 2) using IFA adjuvant. Further, conducting immunization by three times with interval 2 weeks. 2 weeks post the third immunization, the treatment mice was infected with $P$. berghei. Blood sampling of mice is coducted through reorbital plexus a day before the first immuniztation (PP1), a week post third immunization (PP2), 24 hours post infection with $P$. berghei, and 6 days post infection with $P$. berghei. Subsequently, from blood plasm obtained was examined IL-12 level by ELISA method and read at $450 \mathrm{~nm}$. The result show pellet gland extract of An. sundaicus provide markedly effect against IL-12. This suggest that mosquito salivary gland of An. sundaicus from Pellet Extract group is able serve as immuno-modulator factors by exciting cellular immune resposes toward Th1.
\end{abstract}

Keywords: IL-12, Plasmodium berghei, Salivary gland extract of Anopheles sundaicus

\section{Introduction}


Malaria is an infectious disease that is still a major public health problem around the world. According to WHO Report (2015), malaria was a parasitic infection disease placing approximately 3,2 billion peoples or nearly half of world populations at risk of contracting malaria and estimated approximately 214 million new cases of malaria with death about 438 000 peoples worldwide. Of the total number of deaths in the world, $70 \%$ or 306 thousands occur in under five years old, and including 209 thousands in children from Africa. Malaria spread in 95 countries with risk level up to $40 \%$. This disease predominantly attack women and children in Africa and Southeast Asia. In addition to causing mortality and morbidity, malarial infection causes significant economic losses, particularly in the developing countries (Coutinho-Abreu and Ramalho-Ortigao, 2010).

Indonesia, as a tropical country is an endemic area with a various tropical diseases, such as malaria, filariasis, leprosy and filariasis or elephantiasis with an increasing number of patient in the last five years. Especially, malaria show some increasing cases particularly out of Java and Bali. Every year more than 15 million peoples are infected by malaria. More than 90 million Indonsian live in the malarial endemic areas. Of approximately 30 million cases of malaria annually, about $10 \%$ only obtaining tretment. Malaria is a re-emerging disease (Arsin, 2012).

The main problem of malarial prevention to date is a difficulty effort to suppress morbidity and mortality rates due to malaria, yet an effective vaccine has not been found Providing protection to the population. Meanwhile, WHO (2000), Sharma and Pathak (2008) described that in effort to control malaria is taking precaution with giving vaccine or vaccination. Various studies have been done to find an effective vaccination. However, the results have not been satisfactory.

Obstacles in the vaccine development are complexity of the life cycles of malaria parasite consisting some stage both in human body and in Anopheline mosquito as its vector (Lavasec, 2007; Targett, 2008). In relation to the complexity of life cycle, it is necessary to effort development of multi-stage vaccine, a vaccine compound which can induce immune response that protective against each stages of Plasmodium falciparum life cycle. As a result from this complex life cycle, therev are constraints in production of vaccine such as antigen polymorphism, less immunogenic antigen and immunosuppressive conditon induced by parasite (Donovan, e al.2007). Therefore, we need a new breakthrough to overcome such problem which one of them is producing vaccine (Greenwood and Motabingwa, 2002).

The effective vaccine should be well targeted to address parasite in various stages of development, producing humoral and cellular immune responses, and activating the memory cell. Thus, this vaccine should be able to lead to exo-erythrocytic form (hepatic stage) and erythrocytic form (blood stage), as well as capable triggering humoral and cellular immune responses, addressing the genetic restriction and stimulating the memory cell (CaroAguilar, et al., 2002). The key of successful of the vaccine development is the emergence of immune responses in host both via inducing antibody which blocking parasitic invasion and trigger the infected hepatocytes to commit suicide program (apoptosis) and reduce the infected cells that circulating in human body(Syaifudin, 2014).

Malarial parasites entering in bloodstream will soon be faced by the body immunity system initiating by natural immune responses and then by the specific immune responses. The natural immune responses are the first effector to provide resistance against infection (Nugroho,dkk.2000). Macrophages are the important effector cells in protection to malaria by direct phagocytosis to Plasmodium, and secreting cytokines to activate the other macrophages, secreting interleukin-12 (IL-12) to stimulate natural killer cells (NK cells) to produc interferon $-\gamma$ (INF- $\gamma$ ), and as antigen presenting cells to lymphocytes-T (Stevenson 
and Riley, 2004; Good and Doolan, 2010). Ability of phagocytosis and macrophage specificity can be enhanced by cytokines produced by lymphocytes-T helper (Th). The cytokines such as TNF- $\alpha$, IL-1, IL-2, IL-4, IL-6, IL-8, IL-10, and IL-12 play an active role in inhibiting the growth of parasites (cytostatic), or cytotoxic and activating function other immunity systems (Nugroho, dkk., 2000; Malaguarnera dan Musumeci, 2002).

Interleukin-12 is the a potent immunomodulatory cytokine that has effectiveness in protection against viral, bacterial, and intracellular parasite infections and a major mediator from natural immunity system to intracellular microbials, and are key inducer from the cellular immunity is being acquired immune response to that microbials. These cytokines are not only increase cell-mediated immune response but also the humoral immunity. Th-1 effectors producing IFN- $\gamma$, will activate macrophages to increase production of IL-12. The concentratioon of Il-12 resulted by macrophages is associated with erythrocytes damage and bone marrow diserythropoiesis (Malaguarnera and Musumeci, 2002, Abbas and Lichtman, 2003).

So far as, this is not yet find the effective vaccine to prevention of malaria. Therefore it necessary make new approaches in the development of vaccines against malaria whi role ch more innovative and play a role in inhibiting the pathogen transmission causing malaria such that is able to cope with their aepidemic with development of Transmission Blocking Vaccine (TBV). TBV is a vaccine blocking transmission of disease by antigen target come from arthropod vector, one of salivary gland of mosquito (Carter, 2000). TBV have purpose to protect the pathogen transmission from vertebrate host infecting host not infected previously (Coutinho-Abreu and Ramalho-Ortigao, 2010).

The arthropod host salivary gland contain a component of vasomodulatory and immunomodulatory (Kamhawi, et. al, 2000; Titus, et al., 2006). To find appropriate immunomodulatory components in main vector of malaria, the salivary gand of $A n$. sundaicus will open new opportunitiy to find the important component as a new target candidate in production of TBV against malaria. To date it is not yet many reasearch on agent function as immunomodulatory from the salivary gland of mosquito and no known whether they are same to all Anopheles species. The aim to this study is to know the effect of salivary gland extract of Anopheles sundaicus against IL-12 level in the white mouse Mus musculus Balb/C after infected with Plasmodium berghei.

\section{Methods}

The salivary gland extract of An. sundaicus is obtained from the larval collection of Anopheline in Kenagarian Sungai Pinang, Kecamatan Koto XI Tarusan, Kabupaten Pesisir Selatan, by using survey method of larval corresponding to WHO standard (1975). Larva is reared in laboratory into adult stage of Anopheline and furthermore identified by using a reference book of Stoker and Koesoemawinangoen (1950) to obtain female An. sundaicus. The preparation of salivary gland is performed by dissection of salivary gland of female mosquito according to WHO (1975), Bruce-Chwatt (1980), and Jariyapan et al., (2007). The animal model used in this study is the white mouse Mus musculus Balb/C obtained from UD.Tiput Abadi Jaya Peternakan Hewan Uji Yogyakarta. The donor mice have been infected with $P$. berghei isolates obtained from Laboratory of Parasitology of Medical Faculty of Brawijaya University in Malang. The reagents for assay were Mouse IL-12 (Interleukin) ELISA Kit (Elabscience®, Catalog No. E-EL-M0726 96T).

Type of this study is a laboratory experimental studies by design the post test only control group using animal model as object of study. The study is carried out in April-June 2017 in the Laboratory of Parasitology of Medical Faculty, Brawijaya University Malang, 
East Java. The samples were 27 female white mice Mus musculus Balb/C 6-8 weeks old, weight 28-32 gram with sample each treatment group is 9 consisting 3 groups: Control group/C (mice immunized/vaccinated with adjuvant + PBS with 1:1 ratio); Pellet extract/P group (mice immunized/vaccinated with salivary pellet extract of An. sundaicus + adjuvant with 1:1 ratio); Supernatant extract group/S (mice immunized/vaccinated with salivary supernatant extract of An.sundaicus + adjuvant with 1:1 ratio). First immunization is using CFA adjuvant and second immunization (booster 1) and third immunization (booster 2) are using IFA adjuvant. Furthermore, do immunization three times with interval 2 weeks, 2 weeks post third immunization the treatment mice was infected with $P$. berghei. Blood plasm sampling is taking via reorbital plexus in eyes a day before first immunization (PP1), a week after third immunization (PP2), 24 hours post $P$. berghei infection, and six days after $P$. berghei infection. Subsequently, the blood plasm obtained is examined for IL-12 level by ELISA method and read at $450 \mathrm{~nm}$. This research has obtained Ethical clearance from Research Ethical Commission Team of Medical Faculty of Andalas University Padang, West Sumatera, Indonesia.

\section{Result}

IL-12 level was obtained from blood plasm of white mice Mus musculus Balb/C immunized with salivary gland extract of An. sundaicus and was infected with P. berghei and measured using ELISA technique at $450 \mathrm{~nm}$.

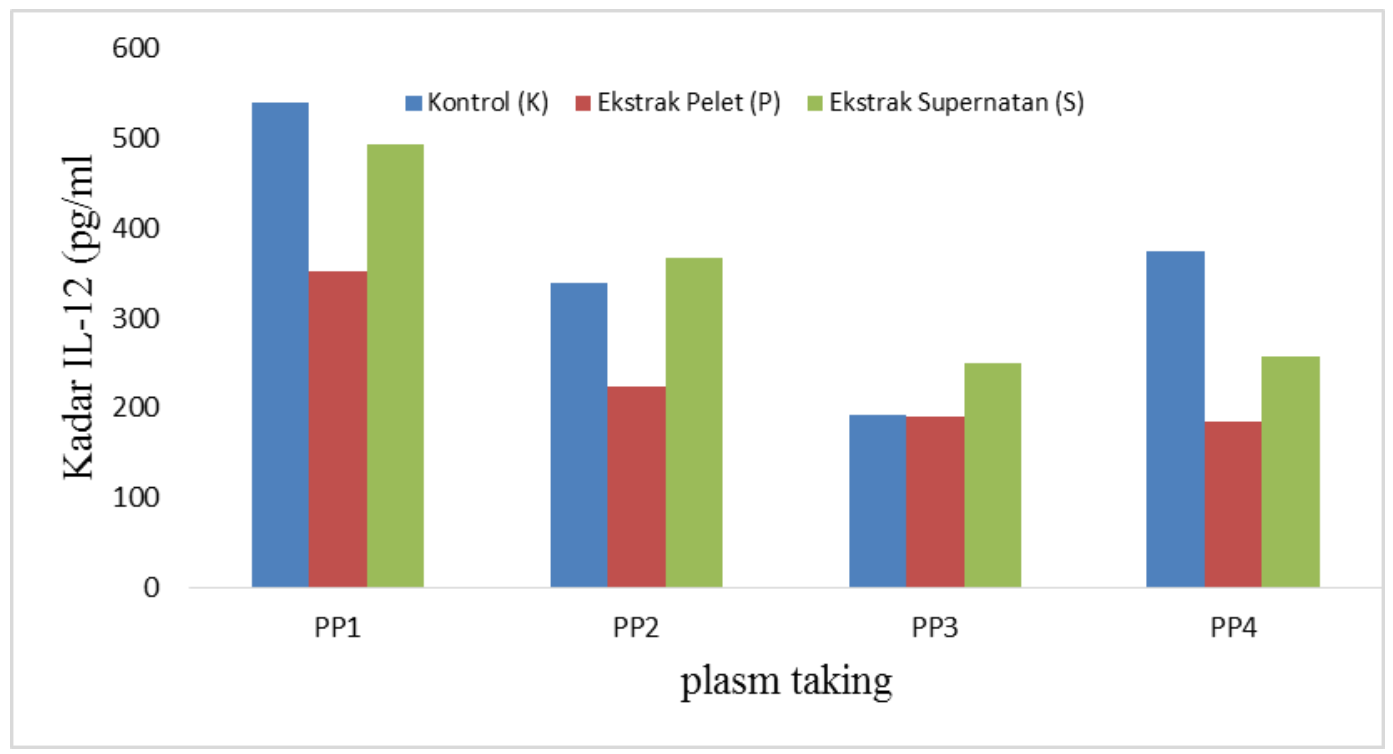

Figure 1. IL-12 levels average from each treatment group

Note: PP1 : plasm taking before first immunization

PP2: Plasm taking after third immunization

PP3: Plasm taking after 24 hours post $P$. berghei infection

PP4: Plasm taking after 6 days post P. berghei infection 
The figure 1 show that according IL-12 level numbers in control group is higher than the supernatant extract and the pellet extract groups. Altough the supernatant extract level decrease, but its level is higher than the pellet extract.

\section{Discussion}

This study observed the influence of salivary gland extract of Anopheles sundaicus to IL-2 levels in the white mouse Mus musculus Balb/C after was infected with $P$. berghei. $P$. berghei infection performed 2 weeks post-third immunization, declining IL-12 level in control group and pellet extract group respectively, and after 6 days of infection, the IL-12 level of supernatant extract group underwent increase than 24 hours of infection.

The statistical test result of ANOVA show that, result obtained is $F_{\text {count }}>F_{\text {table }}$ at stage $0,05 \%$ between administration of salivary gland extract of An. sundaicus with IL-12 level. Tukey Advanced Test-HSD inter group, there are significant difference $(\mathrm{P}<0,05)$ between control group with pellet extract group, but is not significant differed with supernatant extract group (Table 1).

Table 1. The IL-12 levels in white mouse Mus musculus Balb/C immunized with salivary gland extract of An. sundaicus and infected with $P$. berghei

\begin{tabular}{|c|c|c|c|c|c|c|}
\hline \multirow{2}{*}{ No } & \multirow{2}{*}{ Treatment } & \multicolumn{4}{|c|}{ Taking IL-12 levels (pg/ml) } & \multirow{2}{*}{ average } \\
\hline & & PP1 & PP2 & PP3 & PP4 & \\
\hline 1 & Adjuvant + PBS (Control) & 541.13 & 339.41 & 192.86 & 374.44 & $361,96^{\mathrm{a}}$ \\
\hline 2 & Pellet extract & 351.67 & 224.34 & 189.67 & 184.39 & $237,52^{b}$ \\
\hline 3 & Supernatant extract & 493.79 & 367.92 & 249.51 & 256.86 & $342,02^{\mathrm{ab}}$ \\
\hline
\end{tabular}

Note: Superscript differed between tretaments show significant the influence differed $(\mathrm{P}<0,05)$.

PP1: Plasm taking before first immunization

PP2: Plasm taking after third immunization

PP3: Plasm taking after 24 hours post $P$. berghei infection

PP4: Plasm taking after 6 days post P. berghei infection

This research show that the salivary gland pellet extract of An. sundaicus a significant difference with the control group and not differ with the supernatant extract to Il-12 levels. This result describe that the immunization with salivary gland of An. sundaicus from the pellet extract performed to white mouse Mus musculus Balb/C infected with $P$. berghei was able to provide effect to Il-12 level. This show that the mos-quito salivary gland of $A n$. sundaicus from Pellet extract group was able to serve as immu-nomodulatory factor by exciting cellularly immune response or toward Th1. This result is suitable to Andrade et al., (2005) and Donovan et al., (2007) opinion , which suggest that base of using mosquito salivary gland as potential target for development of Transmission Blocking Vaccine was the precsence of putative mosquito salivary gland having immuno-modulatory protein effected to host immune responses. The Mosquito salivary gland is able producting both humoral and cellular immune responses. The presence of re-exposure to sterile mosquito salivary gland has proved able to modulate immune response toward T-helper cells (Th-1) which more benefit to host (immunoprotective).

Furthermore, Andrade (2005) adds that recurrent exposure to mosquito vector bite with salivary gland antigens causes host immune system generating cellular reaction at the 
site of bite, resulting in rejection of ectoparasites. The host resistances is related to Th-1 immune response by the presence interferon- $\gamma$ (IFN- $\gamma$ ), interleukin-2 (IL-2) and IL-12 production. Previous research (Donovan,2007) described that the immune response appears more direct to Th-1 characterized by increased IFN- $\gamma$ and IL-12. Increased cytokine is paralel to decrease parasitemia rate in liver and blood. This suggest that protein induction of vector salivary gland is capable providing protection to host against parasite infection.

\section{Conclusion}

The administration of salivary gland pellet extract of An. sundaicus provide significant effect against IL-12 level in white mouse Mus musculus Balb/C infected by Plasmodium berghei.

\section{References}

Abbas AK, Lichtman AH. 2003. Cellular and Molecular Immunology. 5th ed. Philadelphia : Elsevier Science; 2003: p.243-74.

Andrade, Teixeira, Barral, dan Barral-Netto. 2005. Haematophagous Arthropod Saliva and Host Defense System: A Tale of Tear and Blood. Annals of the Brazilian Academy of Science. Vol. 77(4): 665-693.

Arsin, A.A. 2012. Malaria Di Indonesia, Tinjauan Aspek Epidemiologi. Penerbit : Masagena Press. IKAPI.

Bruce-Chwatt, L.J. 1980. Essential Malariology. William Heinemann Medical Books Ltd, London, pp97-127.

Coutinho-Abreu, I.V. \& Ramalho-Ortiago, M. 2010. Transmission Blocking Vaccine to Control Insect-Borne Disease: A Review. Mem Inst Oswaldo Crus, Rio de Janeiro. Vol. 105 (1): 1-12.

Donovan, Messmore, Scafford, Sacks, Kamhawi, dan McDowell. 2007. Uninfected Mosquito Bites Confer Protection against Infection with Malaria Parasites. Infection and Immunity. Vol. 75 (5): 2523-2530.

Greenwood, B., \& Mutabingwa, T., 2002. Malaria in 2002. Nature. Vol 415.

Jariyapan, Choochote, Jitpakdi, Harnnoi, Siriyasatein, Wilkinson, Junkum, Bates. 2007. Salivary Gland Proteins of The Human Malaria Vector, Anopheles Dirus B (Diptera: Culicidae). Rev. Inst. Med. Trop. S. Paulao, Vol. 49 (1): 5-10.

Kamhawi, Belkaid, Modi, Rowton, dan Sacks. 2000. Protection against cutaneus Leishmaniasis resulting from bite of uninfected sand flies. SCIENCE. Vol.290: 13511354.

Lavazec, Boudin, Lacroix, Bonnet, Diop, Thiberge, Boisson, Tahar, dan Bouorgouin. 2007. Carboxypeptidases Bof Anopheles gambiae as Targets for a Plasmodium falciparum Transmission-Blocking Vaccine. Infection and Immunity. America. Vol 75 (4): 16351642.

Sharma, S. \& Pathak, S. 2008. Malaria Vaccine: A current Perspective. J Vector Borne Dis. India Press. Vol. 45:1-20.

Stoker, W.J., Koesoemawinangoen, R.W. 1950. Buku-Gambar Njamuk-Anopheles dari Indonesia. Penerbit: Kemeterian Kesehatan (bagian Pusat Pemberantasan Malaria) Republik Indonesia. Djakarta, 1950.

Sutisna P. 2003. Malaria secara ringkas dari pengetahuan dasar sampai terapan. Edisi pertama. Jakarta: EGC; 2003:48-53. 
Targett, G.A \& Greenwood, G.M. 2008. Malaria Vaccine and Their Potential Role in The Elimination of Malaria. United Kingdom: Biomed Central Ltd. Malaria Journal. Vol. 7 (1): 1-9.

World Health Organization. 1975a. Division of Malaria and Other Parasitic Diseases. Manual on Practical Entomological Field Techniques For Malaria Control. WHO, Geneva.

World Health Organization. 2000. Malaria Transmission Blocking Vaccines: An Ideal Public Good. Geneva: WHO Press.

World Health Organization. 2015. World Malaria Report 2015. Diakses 25 Juli 2016. http://www.who.int/malaria/publications/world-malaria-report-015/report/en/ 